\title{
Economic and Monetary Prospects : a Spanish Point of View *
}

\author{
by Fernando Abril Martorel **
}

The gradual rapprochement between Spain and the European Economic Community, and our now imminent integration in EEC, will clearly demonstrate - and there can be no doubt on this score - the necessity of a series of reforms - in the insurance sector as elsewhere - capable of turning the insurance trade into an authentic instrument for providing safeguards in an unsafe world. Indeed, if there is one distinctive feature marking today the economic future of our peoples, it is a high degree of insecurity. The question which should be put at the outset of any kind of discussion of our present circumstances, which are fairly common in the free world, is the following: What is politics doing for the economy of nations ?

Our times are not easy ones for the making of forecasts with any degree of precision. The art of forecasting is made every day more difficult in a world which is full of uncertainties, which has been facing an almost universal economic crisis for six years now and which has to deal with such serious problems as the energy crisis, calling for thorough going reforms and adjustments. The international monetary disarray, which the floating exchange rates appear to have accentuated, the great increase in public spending in the last few years, the problems existing with regard to certain basic industries, the ever-increasing unemployment, inflation and slow growth, are some other of the features of this complex era in which we are living.

Nevertheless, it is not possible to renounce to some measure of programming, to the responsibility for regulating economic activities, however liberal one's point of departure may be. The monetary aspects, both internal and international, such as those relating to public spending and public revenue, constitute eloquent examples in this respect. It is difficult nowadays for one country alone to give up all controls over the movement of the monetary mass or to introduce any more or less open intervention in the international quotation of its currency.

In Spain, monetary policy focuses its attention on the growth of the quantity of currency in circulation in the broad sense - in its $M_{3}$ form - and on regulating its growth through the controls imposed on liquid assets. All this is done because of the feeling that it is that particular variable which best reflects the evolution of total demand, and the one which can be controlled most efficiently. Moreover, like in other countries, the monetary policy of Spain is assigned tasks which are not fundamental but are nevertheless relevant to the overall strategy of economic policy.

* Presented in Madrid to the General Assembly of the "Geneva Association" on 9th July 1979.

** Vice-President of the Spanish Government. 
Thus, in 1978, in pursuance of the economic adjustment programme applied by our Government, and with the consent of the other parliamentary political forces, an agreement which was embodied in the so-called "Pactos de la Moncloa", the monetary policy has contributed to the significant reduction of the rate of inflation and has played a fundamental role in the considerable slowing down of the rise in prices - from 26.5 per cent in 1977 to 16.5 per cent in 1978 , measured as per the index of consumer prices from December to December - registered in the past financial year by our economy.

As has occurred in certain other countries - Germany and Switzerland being clear examples in this respect - the efforts to control the growth of the money supply had to contend both with the obstacles arising from the great increase in reserves as a result of the restrictive monetary policy, of the liberalization of the financial system and of the abundance of international liquidities.

It is sufficient to point out in this connexion that in the last two years, from July 1977 until the present time, the foreign currency reserves of Spain have risen from a little more than \$US 3,000 million to over \$US 12,000 million. The balance of trade surplus both in current account and in capital account, and the corresponding rise in reserves and consequent injection of liquidity into the system, have been basically the origin of the problems of monetary control which we have experienced in the past financial year and which, in one way or another, continue in the present year. The weakness of the dollar has obviously influenced this situation, despite the effectiveness which the measures taken on 1st November of the past year may have had.

In situations such as the one described above it seems quite obvious that foreign exchange flexibility constitutes a line of defence of the autonomy of the internal monetary policy. In the past fourteen months, the peseta has risen considerably against all other currencies, but this has not been sufficient to slow down in any significant manner the expansion of the foreign sector, owing to the fact that the chief items of our balance of payments are not sufficiently sensitive to short-term fluctuations of the foreign exchange rate, and to the fact that the Spanish economy still has a high level of protectionism in certain sectors and of general interventionism in the foreign exchange market.

Another source of problems for the monetary policy is the public sector, its deficit and its financing. In this sense, the limitation of public spending - which is sought nowadays by so many European countries - and the financing through a diversified public debt at market prices, constitute absolutely essential steps to take.

At this very moment, we are considering the goals for a monetary policy for the second part of this present year. No attempt will of course be made to solve the problems of the real economy with measures of a monetary kind. But there can be no doubt that recent events in the realm of oil prices suggest that prudence is called for in the financing of its inflationary effects, without losing sight of the long-term and medium-term objectives which must continue to govern the strategy of this policy, in the contribution which it will make to the task of curbing the rising trend of prices.

In any case, monetary policy is part and parcel of economic policy and it must faithfully serve its overall objectives. The prospects of the Spanish economy, like those of any other country at our same level and stage of development, have been 
gravely affected by the steep rise in oil prices agreed on in Geneva at the end of the month of June last.

For this year, we had programmed for a growth of the order of 4 to 5 per cent and an inflation rate of 12.5 to 13 per cent. Today it can be safely asserted that the growth objective is going to be $1 / 1.5$ per cent below the original estimate and that the inflation rate will rise by two points. Similar changes of objectives - and in the same direction - are becoming normal in all the countries which are highly dependent on imported energy. The OECD and IMF have just revised downwards their estimates for growth and their forecasts regarding the rise of inflation rates.

It is obvious that the prospects of the Spanish economy - for this year and in the medium-term - are very much conditioned, not only by the success of the policy of economic adjustment and reform undertaken two years ago, but also by the rate of growth of the industrialized countries and by the economic policies which they follow in the present juncture. At present, it seems less likely that the rate of economic growth of the countries members of OECD can be higher than $3 / 3.5$ per cent as an average during the next five years, a rate which can moreover be adversely affected by the consequences of the energy crisis, both as regards its price effects and as regards shortage of supplies.

The economic prospects of Spain will be necessarily influenced by the greater or lesser success which we will achieve in the field of the struggle to control inflation. During the past few years, the rates of increase of prices in Spain have been considerably higher than the average for all the countries members of OECD, although this difference has decreased substantially during the past year and a half. This objective of closing the gap between our prices and those of the countries with which we have most of our trade relations cannot be abandoned in any way. And to persist in the pursuit of this objective would require the adoption of policies for the strict control of demand.

In addition, the attitude adopted by the taxation authorities is of special importance in avoiding adverse effects upon price movements by means of policies calculated to compensate for losses in real income caused by the rise in energy prices. These price rises imply, as has so often been said, a deterioration in our balance of payments position and a fall in our production and it would serve no useful purpose to try to make up for these losses merely by raising money incomes.

The linking of money salaries to the level of prices of a recent past has the effect of merely perpetuating inflation without ensuring the maintenance, and still less the growth, of real salaries.

At the present moment, there is also great concern at the developments in the public sector, which has experienced a considerable increase in its deficit in recent months and which is now creating problems for the monetary policy of the country and for the private sector with regard to the share of financing corresponding to that sector. The Government is making considerable efforts in order to curb the growth of public spending and to increase its efficiency.

It is more than likely that the high rates of economic growth which have been recorded until now have been due to exceptional circumstances - namely cheap 
energy, a comparatively simple technological development and especially favourable political and economic conditions. In the future, we can expect rates of growth to be lower and the productive process - which will be more weekly fed and of an increasing complexity - to demand, through the agency of international solidarity, the necessary security to afford maximum stimulation to the factors of development.

It is a generally recognized phenomenon that economic growth and, above all, economic development, with its connotations which are not only quantitative but also qualitative in scope, shows an increasing complexity, a greater interdependence between the production factors and, in the relations between the various national economies, a higher rate of capitalization and, in the last instance, a greater measure of vulnerability.

Growth, which is more than proportional as regards the GNP of insurance in the western world, provides a first indication of the existence of the above-mentioned phenomenon, which results in an increasing necessity to achieve new standards of security.

From a sociological standpoint, it is clear that in a free and democratic society and system like those of Spain and the other Western European countries, security tends to be achieved without detriment to freedom.

This is possibly a favourable moment for asking ourselves whether the institutions involved in the creation of this type of security are in a position to respond satisfactorily to the demands of more complex - and possibly less powerful - economies, and to the growing needs of security on the part of individuals, firms and the community as a whole.

I have the impression that for many years the insurance world in general, and the Spanish insurance world in particular, has lived in a sort of comfortable ivory tower, self-sufficient in its complex legal and actuarial techniques and somewhat far away from the problems which large part of society and of the other economic sectors have had to face.

At present, I believe that special importance must be attached to the study of insurance economics. Its adaptation to existing needs is illustrated by the objective which it has adopted of placing insurance problems in the context of the modern economy and modern society; and also in the objective of seeking to bring about the emergence, above possible antagonisms between economic factors, of the interest which they all have in facing together the problem of risk in a rapidly developing world, in which persons feel a growing desire for security in freedom.

In this sense, it is satisfactory to note the success of the Geneva Association.

Personally I am convinced that the Spanish insurers are aware that they must accept profound changes in order to adapt themselves to the needs of security which emerge from the uncertainties arising from a crisis with the characteristics of the one that the whole of the western world has been experiencing for the past six years. Insurance must be an instrument for providing guarantees of personal freedom, as well as an important stimulating factor for economic activity. especially through its function in the channelling of savings and in long-term investments. 
These two contributions of security and personal freedom on the one hand, and of an element of non-inflationary financing for economic development on the other, represent the two great challenges which the Spanish insurers have to face.

These, of course, are not the only aspects which condition the economic prospects of Spain. But these thoughts have purported to point briefly to some of the subjects which concern today those of us who have responsibilities in the shaping of economic policy. Times are difficult, but it is precisely in these moments that the capacity of a country to move ahead is tested. Spain has given proof of great potentialities in finding solutions for its political problems, in the transition from an authoritarian regime to a democracy. I am sure that in the face of the present economic crisis as well, a crisis which is at present affecting the whole world, we will be able to overcome these difficulties, and show once more satisfactory growth rates which will ensure the creation of a sufficient number of new jobs and the raising of the levels of well-being attained by the population. 